\title{
Evaluation of the effectiveness of the use of free diced cartilage in dorsal and tip nasal rhinoplasty
}

\author{
Amr Gouda Shafik, Mohamed Naguib Mohamed and Hassan Mohamed Hassan*
}

\begin{abstract}
Background: Rhinoplasty is considered one of the most challenging operations in the plastic surgery. Esthetic or functional reshaping purposes of the nose can be stressing for both surgeon and patient. Different types of graft materials have been used to perform augmentation rhinoplasty. Free diced cartilage (FDC) was recently established in dorsal nasal rhinoplasty for better handling of irregularities as well as contour deficits of dorsal nasal outcomes. The main purpose of the present study is to assess the effectiveness of the use of FDC in dorsal nasal and nasal tip rhinoplasty and evaluation of its advantages and disadvantages using the validated Nasal Obstruction Symptom Evaluation (NOSE) scale and the Rhinoplasty Outcome Evaluation (ROE) questionnaire to assess nasal obstruction and patient satisfaction.

Results: This prospective study was conducted between March 2018 and December 2019, 20 patients were included and planned for rhinoplasty using FDC to camouflage dorsal and nasal tip deformities. All patients (11 males and 9 females) underwent open rhinoplasty through inverted $v$ columellar incision, taken FDC from nasal septum. A statistical significant difference between pre- and post-operative NOSE scores was found $(P<0.001)$. Postoperative rhinoplasty outcome evaluation scores ranged from 45 to 100 with mean \pm SD (83.15 \pm 13.22$)$. Excellent satisfaction was the most noted in 17 patients (85\%), while 2 patients (10\%) reported good satisfaction and 1 patient (5\%) with acceptable satisfaction.
\end{abstract}

Conclusion: It was found that the FDC technique is an effective method for camouflage and augmentation of nasal dorsum as well as nasal tip in reconstructive and esthetic rhinosurgery for either primary or secondary rhinoplasty.

Keywords: Free diced cartilage, Rhinoplasty, NOSE scale

\section{Background}

Rhinoplasty remains one of the most challenging operations in plastic surgery field. The interplay between the functional and the cosmetic outcomes is the great concern for both surgeon and patient. A lot of debates regarding the main indications needed and techniques used remain uncovered [1].

Many types of graft materials have been used to perform augmentation rhinoplasty. Those materials can be

\footnotetext{
*Correspondence: drhassan1982m@gmail.com

Department of Otorhinolaryngology, Faculty of Medicine, Ain Shams University, Ramsis St., El Abasseya Square, Cairo, Egypt
}

divided into two principal categories: autologous and non-autologous types of materials [2].

Autogenous cartilage is commonly used for nasal augmentation and is likely considered to be the ideal grafting material owing to its versatility [3], long-term survival, and absence of immunogenicity [4].

The technique of diced cartilage graft can prevent the complication of solid-cartilage graft owing to its small fragment size. The challenge with this technique is attributed to the well-controlled insertion of the graft and post-operative graft visibility and motility prevention [5].

\section{Springer Open}

(- The Author(s). 2020 Open Access This article is licensed under a Creative Commons Attribution 4.0 International License, which permits use, sharing, adaptation, distribution and reproduction in any medium or format, as long as you give appropriate credit to the original author(s) and the source, provide a link to the Creative Commons licence, and indicate if changes were made. The images or other third party material in this article are included in the article's Creative Commons licence, unless indicated otherwise in a credit line to the material. If material is not included in the article's Creative Commons licence and your intended use is not permitted by statutory regulation or exceeds the permitted use, you will need to obtain permission directly from the copyright holder. To view a copy of this licence, visit http://creativecommons.org/licenses/by/4.0/. 
Free diced cartilage (FDC) was recently established in dorsal nasal rhinoplasty for better handling of irregularities as well as contour deficits of dorsal nasal outcomes. FDC technique was reported to handle the dislodgment problem and it permitted proper fitness due to its plasticity. Hence, free diced cartilage may be a promising method for reducing post-operative outcomes [6].

This study aimed to evaluate the effectiveness of the use of free diced cartilage in dorsal and tip nasal rhinoplasty.

\section{Methods}

Prospective study was conducted between March 2018 and December 2019. Twenty patients were included and planned for rhinoplasty with FDC for dorsal and nasal tip deformities camouflaging.

\section{Inclusion patient's criteria}

Both sexes were included with dorsal or tip nasal deformity for both post-traumatic and non-traumatic indications of either primary or secondary correction.

\section{Exclusion patient's criteria}

Congenial or non-traumatic deformity, children, pregnant females or lactating females, cardiac insults, autoimmune problems, renal or liver impairment, and recent local or systemic infection within the last month.

\section{Surgical technique}

Cartilage was picked without perichondrium from the nasal septum, the rib, the tragus, or concha of the ear. Then, the cartilage was slit and diced into pieces less than $0.2 \mathrm{~mm}$ in diameter (Fig. 1). Throughout the dicing process, an adhesive effect through surface tension was
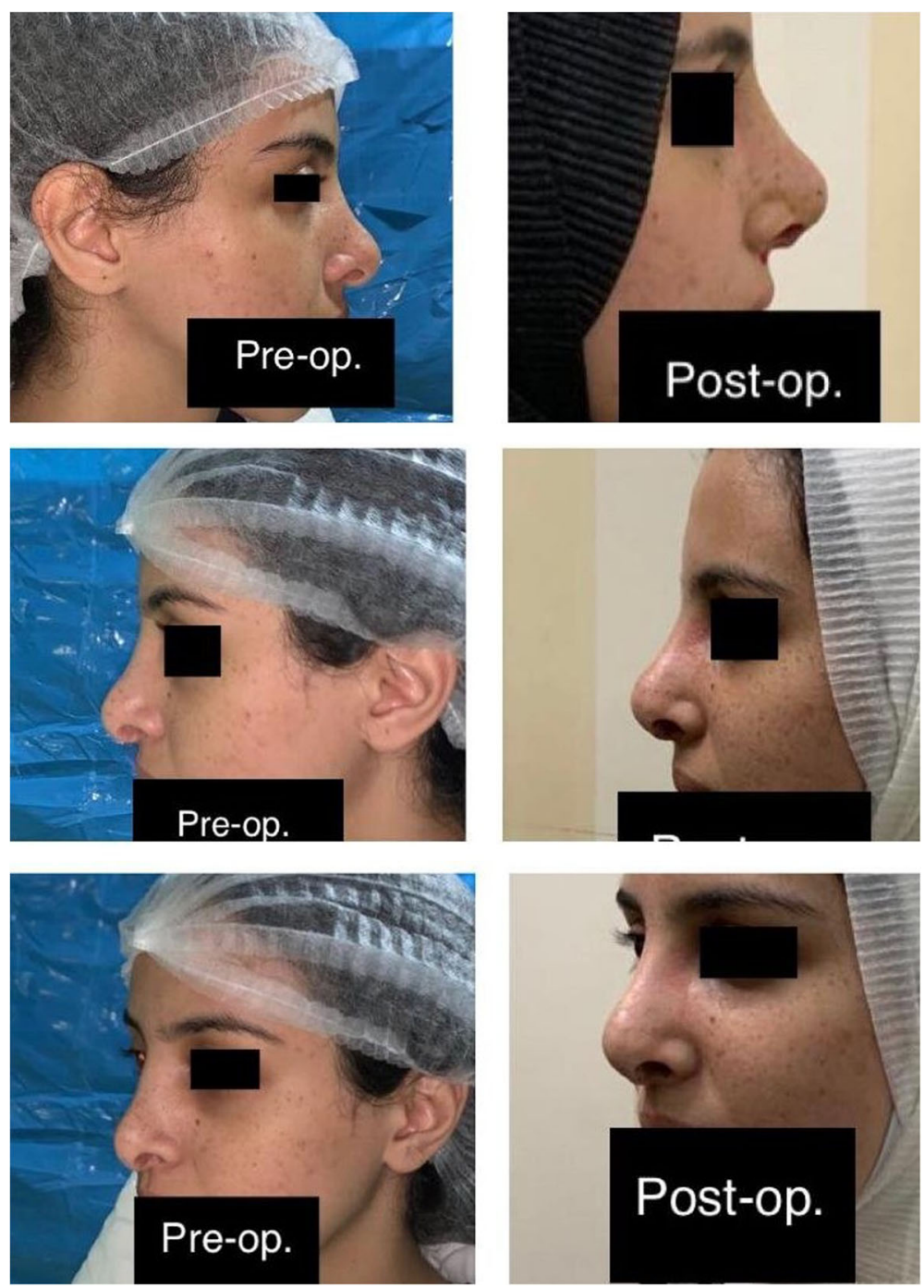

Fig. 1 The cartilage taken was silt and sliced into pieces of diameter less than $0.2 \mathrm{~mm}$ using sharp blade no. 11 
gained by using small amounts $(1-3 \mathrm{ml})$ of normal saline $(\mathrm{NaCl})$ or gentamicin solution. Throughout the cutting process, in order to maintain viability of the chondrocytes, it was vital not to squeeze the cartilage. Eventually, a fine-particle FDC granulate was constructed, featuring characteristics of a malleable paste. The FDC paste was filled into a 1-ml syringe dried and in the end, injected directly into the desired region or by raspatorium. When applied FDC to the nasal dorsum, we massaged and directly fixated it with a paper drape. At the end of the procedure, we completed our surgery by application of steristrips and external nasal stent. Removal of the stitches was done at the first post-operative visit at the 7 th post-operative day at the time of removal of the outer nasal cast. Follow-up visits were scheduled monthly for the first 6 months then every 2 months for the 12 months. The evaluation was based on inspection and photographic documentation. In addition, patient satisfaction was assessed by direct questioning in the post-operative follow-up visits. In the present study, two questionnaires were used. The validated Nasal Obstruction Symptom Evaluation (NOSE) scale to assess nasal obstruction and the Rhinoplasty Outcome Evaluation (ROE) questionnaire was used also in this study to evaluate the patients' satisfaction level post-operative only $[7,8]$. Both NOSE score and ROE questionnaire were translated into the native language (Arabic) with the same methodology $[9,10]$.

A written informed consent was obtained from all patients for the use of FDC graft. The study was approved by the local medical ethical committee and in accordance with the Helsinki Declaration of 1975.

\section{Statistical analysis}

Data were fed to the computer and analyzed using the IBM SPSS software package version 20.0. (Armonk, NY: IBM Corp). Kolmogorov-Smirnov, Shapiro, and D'agstino tests were utilized to confirm the normality of distribution of variables. Comparisons between the different stages for categorical variables were assessed using Marginal Homogeneity Test; Paired $t$ test was assessed for comparison between different periods for normally distributed quantitative variables. $P$ value $<$ 0.005 was considered significant.

\section{Results}

Twenty patients were included in the current study. Their ages ranged from 18-53 years old. They included 11 (55\%) males and 9 (45\%) females. Eight (40\%) patients seeked for operation post-traumatic insults, while 12 (60\%) patients for cosmetic purposes. Primary rhinoplasty was considered for 17 patients (85\%) and 3 patients (15\%) underwent secondary type of rhinoplasty.
Table 1 Distribution of the studied cases according to NOSE questionnaire $(n=20)$

\begin{tabular}{llll}
\hline NOSE score & Pre-operative & Post-operative & $P$ \\
\hline Mild $(5-<25)$ & $6(30 \%)$ & $20(100 \%)$ & ${ }^{\mathrm{MH} P}<0.001^{*}$ \\
Moderate $(30-<50)$ & $7(35 \%)$ & $0(0 \%)$ & \\
Severe $(55-<75)$ & $6(30 \%)$ & $0(0 \%)$ & \\
Extreme $(80-100)$ & $1(5 \%)$ & $0(0 \%)$ & \\
Mean \pm SD & $43.5 \pm 25.4$ & $12.5 \pm 5$ & ${ }^{\mathrm{t}} P<0.001^{*}$ \\
Median (min.-max.) & $50(5-80)$ & $15(5-20)$ & \\
\hline
\end{tabular}

$M H$ marginal homogeneity test, $t$ paired $t$ test

$P P$ value for comparing between pre-operative and post-operative

"Statistically significant at $P<0.05$

According to Table 1, in the pre-operative phase, 6 (30\%) patients had mild NOSE score, while 7 (35\%) patients, $6(30 \%)$ patients, and $1(5 \%)$ patient were presented with moderate, severe, and extreme NOSE score respectively. In the post-operative phase, all studied patients (100\%) presented with mild NOSE score. A statistically significant difference between pre- and postoperative NOSE scores $(P<0.001)$ was found. Preoperative NOSE scores (mean \pm SD) were $43.5 \pm 25.4$ and ranged from 5 to 80 , while post-operative scores (mean $\pm \mathrm{SD}$ ) were $12.5 \pm 5$ and ranged from 5 to 20 . Accordingly, a significant lower scores of nasal obstruction symptoms were obtained post-operative than preoperative scores $(P<0.001)$.

According to Table 2, post-operative rhinoplasty outcome evaluation scores ranged from 45 to 100 with mean \pm SD $83.15 \pm 13.22$. Excellent satisfaction was the most noted in 17 patients (85\%), while 2 patients $(10 \%)$ reported good satisfaction and 1 patient (5\%) with acceptable satisfaction.

All patients were satisfied with esthetic and functional outcome and did not need revision surgery. Cosmetic appearance improved in all cases both subjectively and objectively (most of them changed their profile picture at the Facebook post-operative). Post-operative followup period was from 6 months up to 18 months. No case showed extrusion of graft was seen in any of the patients. One patient developed self-limited allergic contact dermatitis from an external nasal splint.

Table 2 Distribution of the studied cases according to postoperative ROE questionnaire $(n=20)$

\begin{tabular}{ll}
\hline Post-operative ROE score & No. (\%) \\
\hline Poor (0-25) & $0(0.0 \%)$ \\
Acceptable $(25-<50)$ & $1(5.0 \%)$ \\
Good $(50-<75)$ & $2(10.0 \%)$ \\
Excellent satisfaction $(75-100)$ & $17(85.0 \%)$ \\
Mean \pm SD & $83.15 \pm 13.22$ \\
Median (min.-max.) & $86.0(45.0-100.0)$ \\
\hline
\end{tabular}




\section{Presentation of some cases}

\section{Case 1}

A 21-year-old female presented with a saddle-shaped nose with deviated nasal septum and alar retraction. She had undergone two times previous rhinoplasty (Fig. 2).

\section{Case 2}

A 34-year-old female presented with droopy nasal tip with alar retraction and asymmetry (Fig. 3).

\section{Case 3}

A 27-year-old male patient complained from posttraumatic nasal obstruction and dorsal nasal malalignment (Fig. 4).

\section{Case 4}

An 18-year-old male patient complained of posttraumatic nasal obstruction with dorsal nasal hump (osseocartilaginous) and alar asymmetry (Fig. 5).
Case 5

A 53-year-old female patient with tension nose and droopy nasal tip (Fig. 6).

\section{Case 6}

A 22-year-old male patient had dorsal nasal malalignment with hump (osseocartilaginous), alar asymmetry, and nasal obstruction (Fig. 7).

Clinical cases pre-operative, post-operative at the end of the follow-up period, and the procedure done were presented in Figs. 2, 3, 4, 5, 6, and 7.

\section{Discussion}

Rhinoplasty is referred as a nose job. It is a plastic procedure for nasal correction and reconstruction. To date, multiple options have been described for augmentation, smoothening, and nasal dorsum and nasal tip camouflaging. Problems reported in rhinoplasty such as residual humps, notching, alar asymmetry, distorted anatomy of the nose, which is more evident in patients with thin skin, and revision rhinoplasty. Variable techniques to
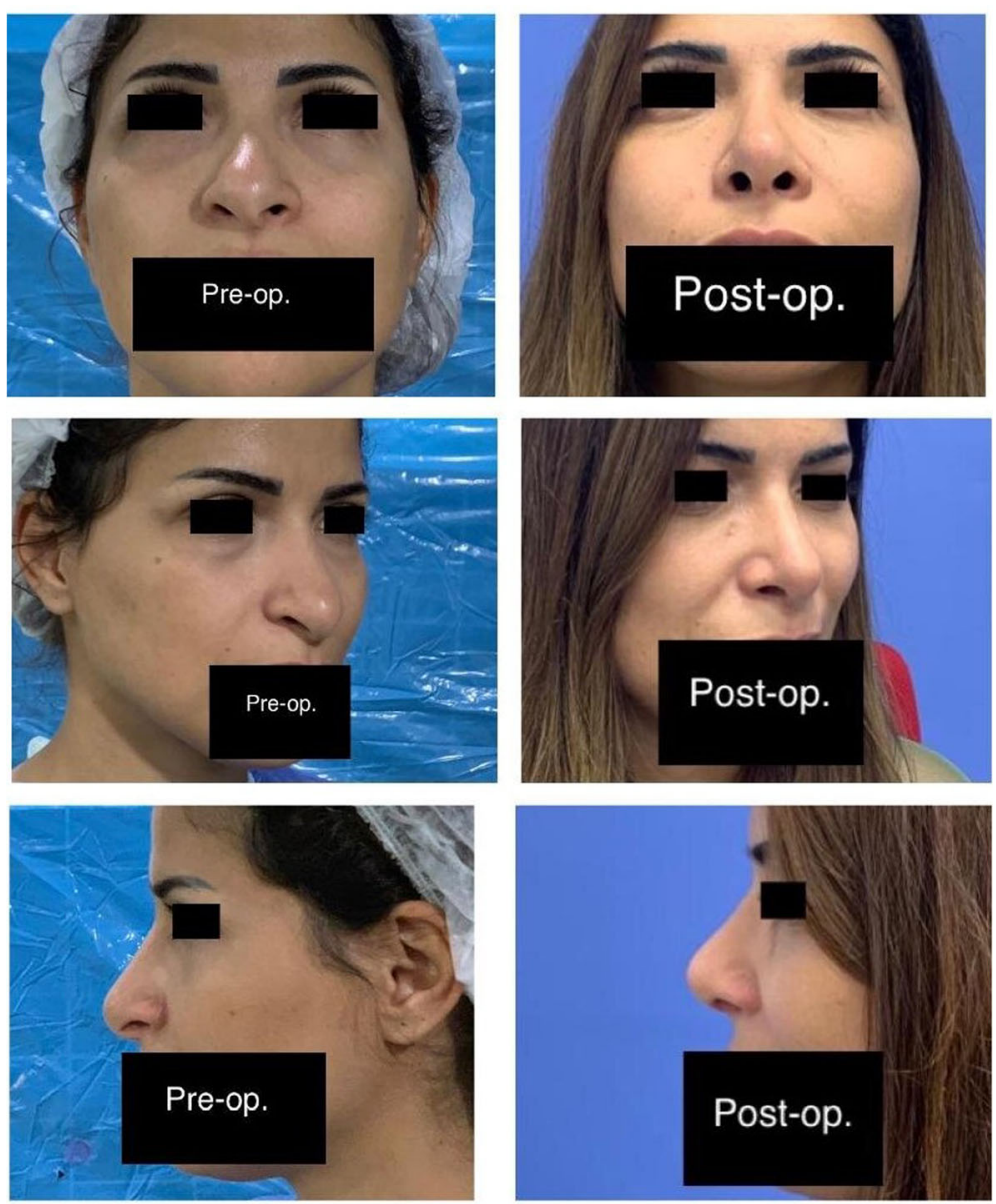

Fig. 2 Case no. (1): 1—open approach septorhinoplasty was done. 2-osteotomies. 3-tongue in groove technique. 4-small filling defect irregularities at the dorsum filled by FDC to smoothen the contour 

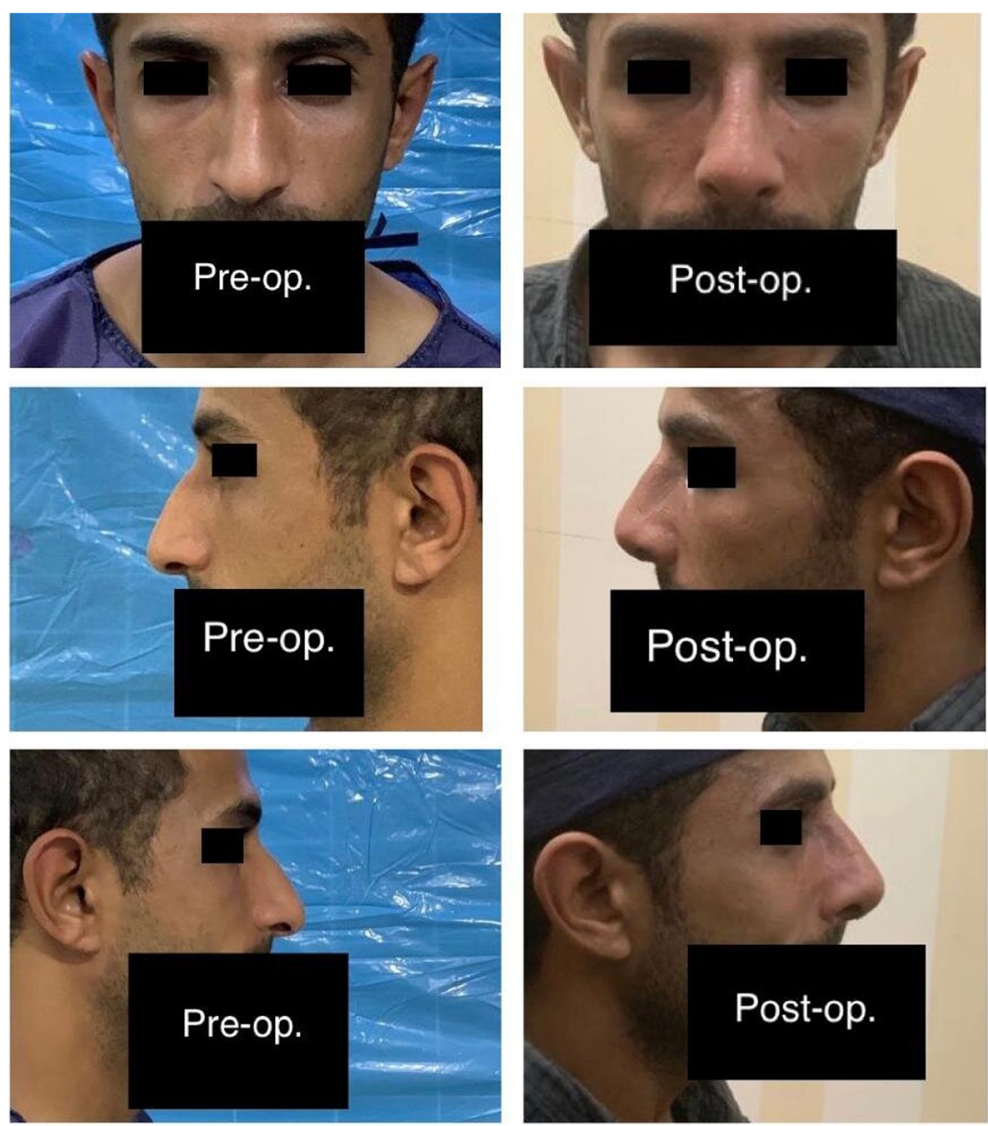

Fig. 3 Case no. (2): 1—open approach septorhinoplasty was done. 2-osteotomies. 3-tongue in groove to elevate nasal tip. 4-buttress graft. 5-finally, FDC inserted at the site of infra tip lobule

avert those irregularities and smoothen both nasal dorsum and nasal tip have been outlined, such as the cylindrical power drill use, the utilization of morselized cartilage grafts [11], or fascia (allogenic fascia lata or autologous deep temporal fascia), diced cartilage in conjunction with a scaffold (fibrin, fascia, or blood glue, acellular dermal matrix, oxidized cellulose) [12-14].

As regards using the morselized cartilage grafts technique on the nasal dorsum, some associated disadvantages were encountered such as secondary dislocation, visibility of the grafts, unexpected resorption [15]. Free diced cartilage avoid these problems as we did not report any graft dislocation or even resorption of FDC on clinical examination during the 18-month follow-up.

On the contrary with using fascial graft (allogenic fascia lata or autologous deep temporal fascia), those grafts showed an initial constant shrinkage by about $20 \%$ within the first 4-6 weeks of post-operative period due to compression and condensation of the fascial fibrous tissue. After its shrinkage, the grafts then become stable and firm [16]. In addition, the use of allogenic fascia adding more cost to such operation.
Vice versa FDC, in the present study, the volume added can be accurately estimated. Also, FDC can be used in combination with allogenic or autologous fascia; however, being a delicate fine granulate, FDC could be utilized without using any bonding material, in order to avoid additional costs and time-saving operative preparation [6].

In agreement with Hoehne et al. [17], our study found that FDC is effective in accurately leveling even the smallest contour deformities as supra nasal break or nasal tip by supplying a precise "filling" of the deformities compared with shaping the nasal dorsum by using a fascial onlays or even diced cartilage in conjunction with a scaffold. In addition, unlike other techniques, FDC can be simply applied even after skin incision closure, permitting an easy and better assessment of the dorsal refinements performed.

On the other hand, after hump removal commonly contribute to an open roof deformity during rhinoplasty. One of the drawbacks of FDC is that this deformity is uncorrectable. In accordance with Erol [18], FDC is not recommended as the best indication for open roof 

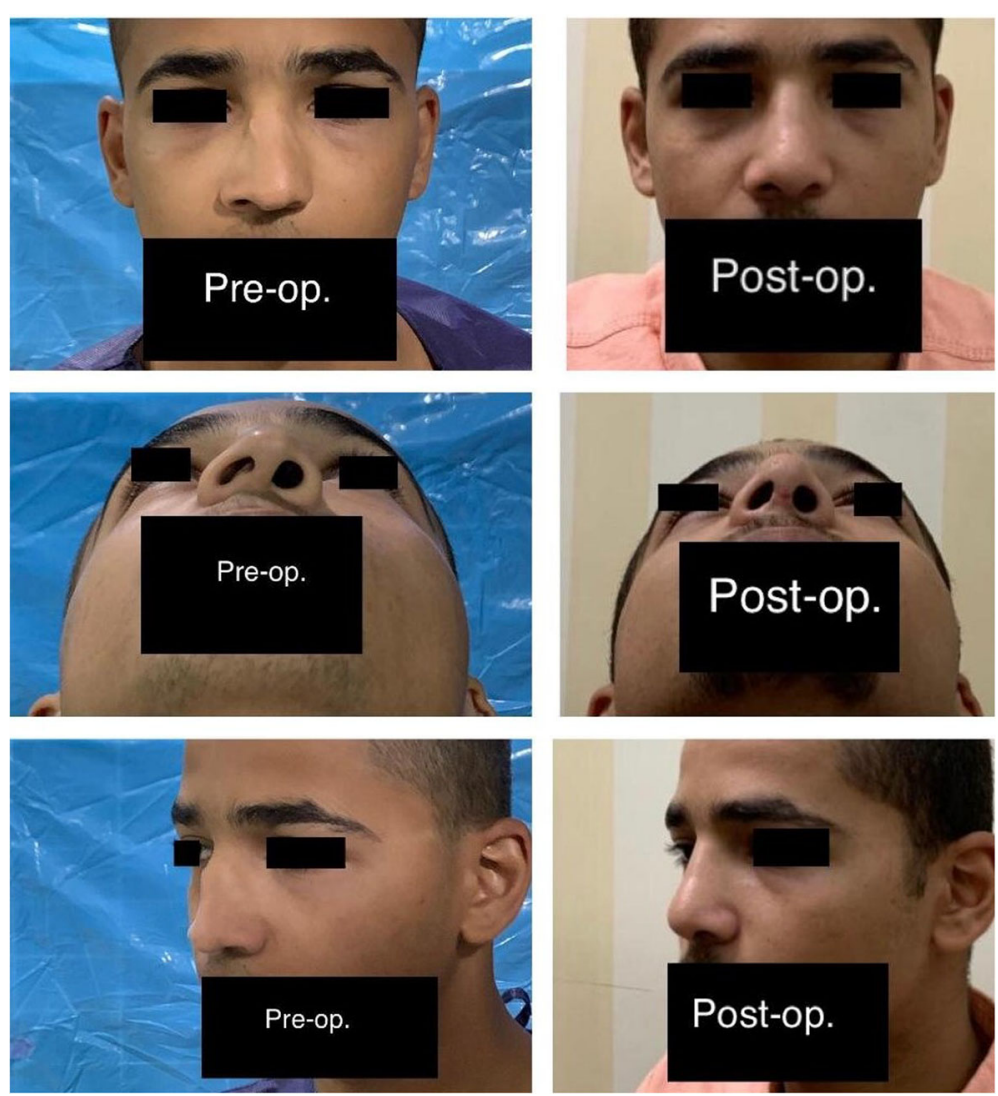

Fig. 4 Case no. (3): 1—open approach septorhinoplasty with bilateral partial inferior turbnectomy. 2-osteotomies. 3—spreader graft to correct nasal deviation. 4-columellar strut was done. 5-finally, FDC at the site of supra nasal tip area

deformity, for instance, wrapped diced cartilage may be preferred, or even the use of bone dust. In fact, FDC should be referred as an ideal method for refinements with mild filling characteristics.

In comparison with Bullocks et al. [14], use autologous tissue glue (ATG) for better stabilization of diced cartilage grafts, thus providing a malleable diced cartilage construction. They reported its advantage that there is lack of a barrier to prevent nutritional diffusion to the chondrocytes within the graft, which results in better cartilage viability. As they utilized bovine thrombin, however, possible drawbacks as immune-mediated coagulopathy and short-term nasal erythema following diced cartilage graft insertion with ATG could occur. It should be noted, however, that in fine diced cartilage of diameter less than $0.2 \mathrm{~mm}$, as described in the current work, cartilaginous nutrition is better facilitated where the surface area is notably enlarged and the diffusion distance decreased compared with larger diced or solid cartilage grafts. In cases of revision surgery, mentioned in different occasions previously applied FDC, fusion with viable block of semisolid cartilage, exhibiting viable chondrocytes on histological sections significantly supporting the theory of better nutritional supply through widening of the surface area and diffusion distance reduction of the fine diced cartilage grafts [17].

In agreement with Kreutzer et al. [6], our study found that all patients were significantly satisfied and did not require revision surgery although post-operative followup was 18 months. On the other hand, there is a great difference that was noted between sample size in both studies of 20 patients in the present work and 325 patients in Kreutzer's study. Kreutzer et al. reported that revision rates for dorsal irregularities within the 7month post-operative follow-up assessment of 5.2\%. These findings strongly support our clinical results. In contrast, when fascia alone or in combination with FDC was used for management of the nasal dorsum, authors observed increased revision rates of $8.2 \%$. They mentioned that the use of diced cartilage facia (DCF) was linked to the highest revision rate (25\%) [6].

According to Hoehne et al. [17], who reported that the use of cylindrical power drill for better reduction of small humps, in addition to, the use of allogenic fascia alone or in combination with diced cartilage for dorsal nasal augmentation is still considered as valuable 

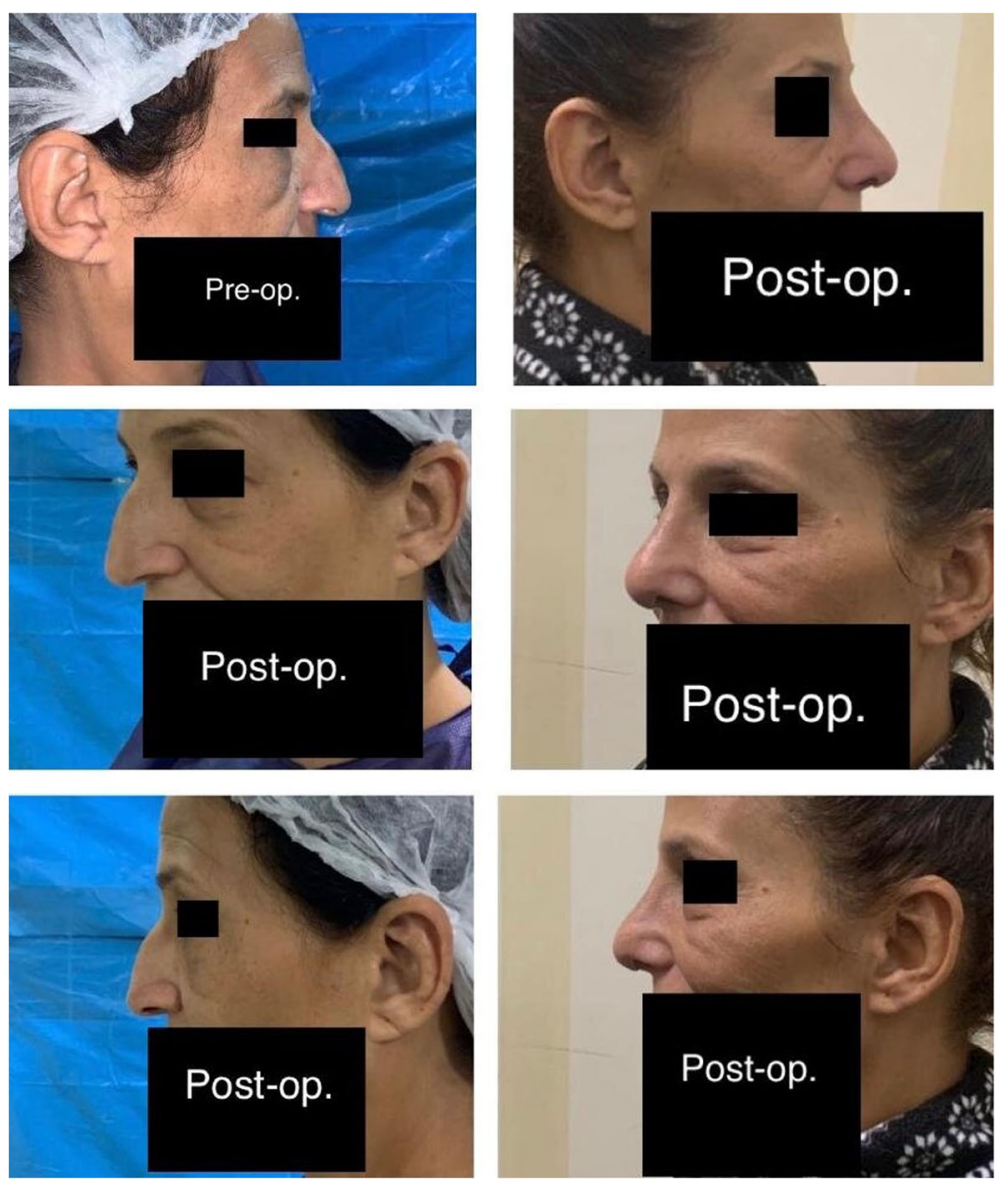

Fig. 5 Case no. (4): 1—open approach septorhinoplasty was done. 2-removal of nasal dorsal cartilaginous hump by blade and removing of osseous hump by rasping. 3-osteotomies were done. 4-columellar strut. 5-finally, FDC at the nasal dorsal was injected

methods in modern rhinoplasty, they suggested that for nasal dorsum smoothening, the routinely application of FDC is recently the perfect technique.

Also, in our study, we used FDC for better blunt view, fullness, tip projection, and filling defect of both supra tip break and infra tip lobule. Free diced cartilage also assists to gain a higher natural-looking appearance in the tip by modulating minimal irregularities soon afterward final closure. Of note, nasal drape should be accurate enough to keep the FDC on site.

Previous studies used NOSE scale in assessment of different studies. Kahveci et al. studied 27 patients and showed that NOSE scale is a significantly efficient method in assessing the consequences of septoplasty. Their patients had significant improvement in nasal obstruction symptoms post-operative septoplasty $(P<0.01)$. The mean pre-operative NOSE score was reported to be 60.2 (SD, 17.45) while the mean post-operative score was shown as 11.28 (SD, 10.45) [19]. Furthermore, Gerecci et al. [20] showed a mean NOSE score of 49 patients improved significantly between pre-operative and early postoperative assessments (71.4, $\mathrm{SD} \pm 17.0$ vs. $24.2, \mathrm{SD} \pm$ 19.5; $P<0.001$ ).

In the present study, a statistical significant difference between pre- and post-operative NOSE score $(P<0.001)$ was found. Pre-operative NOSE scores (mean \pm SD) were $43.5 \pm 25.4$ and ranged from 5 to 80 , while postoperative scores (mean $\pm \mathrm{SD}$ ) were $12.5 \pm 5$ and ranged from 5 to 20. Accordingly, significant lower scores of nasal obstruction symptoms were obtained postoperative in comparison to post pre-operative scores $(P<0.001)$.

Another validated questionnaire was formerly tested by Alssarraf et al. [21], the ROE questionnaire used in the current study to assess the outcome of the procedure.

For 45 patients of Arima et al. [22], who went through rhinoplasty, the average pre-operative satisfaction score was shown to be $24.6 \pm 11$. Three using the ROE questionnaire, while the average post-operative score was reported to be $76.1 \pm 19.5(P<0.0001)$. 

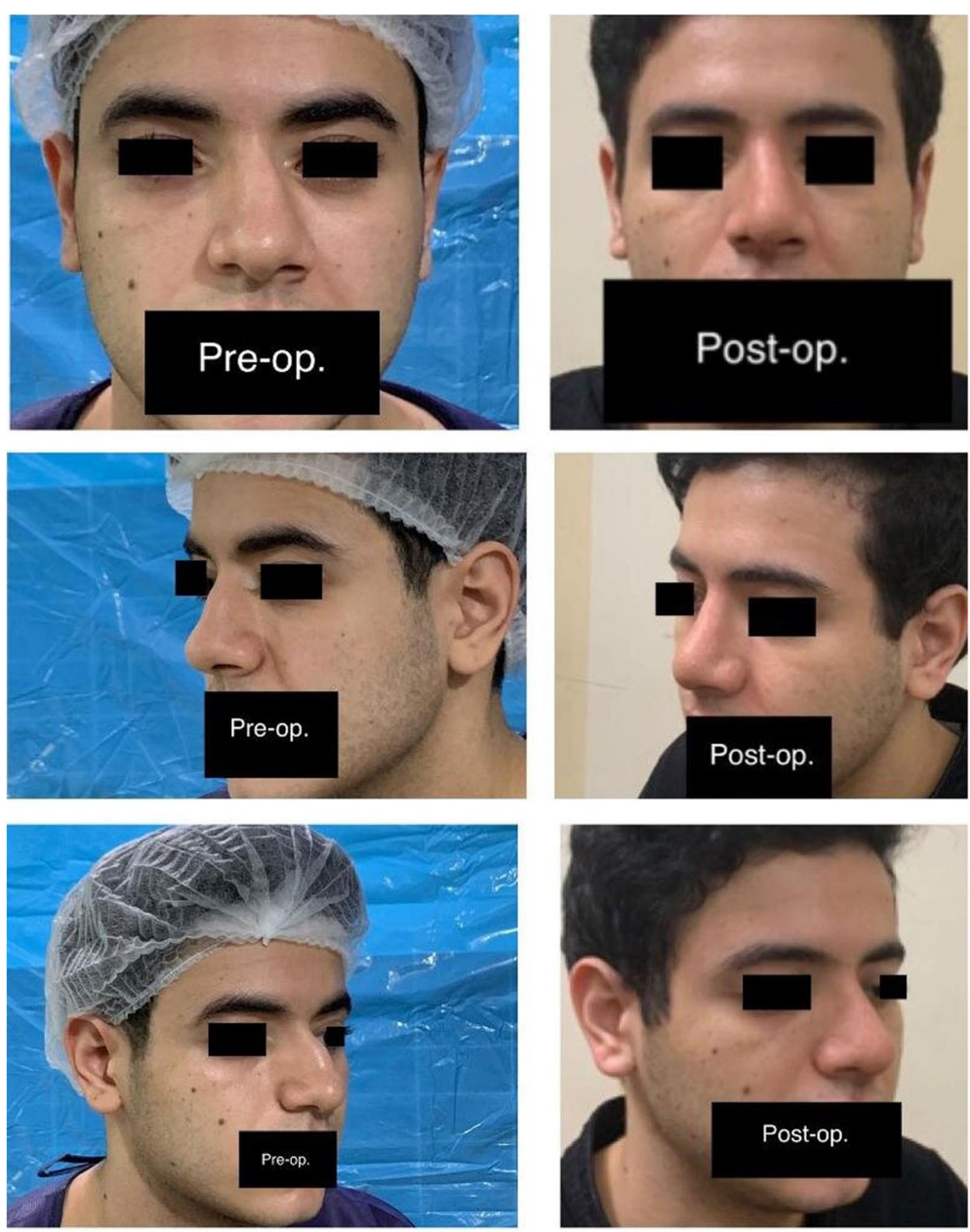

Fig. 6 Case no. (5): 1-open approach rhinoplasty. 2-rasping was done. 3-osteotomies. 4-tongue in groove was done to elevate nasal tip. 5-FDC inserted at the nasal tip to increase tip definition

Using the ROE questionnaire, in our study postoperative rhinoplasty outcome evaluation showed scores ranged from 45 to 100 with mean \pm SD $(83.15 \pm 13.22)$. Excellent satisfaction was the most noted in 17 patients (85\%), while 2 patients (10\%) reported good satisfaction, and 1 patient (5\%) with acceptable satisfaction.

\section{Conclusion}

Free diced cartilage is an efficient method for augmentation and camouflaging of nasal dorsum as well as nasal tip in both reconstructive and esthetic rhinoplasty for either primary or secondary rhinoplasty. Further studies with larger sample size and long-term results should be done for further support of the reported results.

\section{Abbreviations}

FDC: Free diced cartilage; NOSE: Nasal Obstruction Symptom Evaluation; ROE: Rhinoplasty Outcome Evaluation; ATG: Autologous tissue glue; DCF: Diced cartilage fascia

\section{Acknowledgements}

Nil

\section{Authors' contributions}

All authors contributed to the study conception and design. Study design was done by AS. Surgical procedures were done by AS and assisted by MM and $\mathrm{HH}$. Data collection was done by $\mathrm{AS}$ and $\mathrm{HH}$. Analysis and interpretation of the data was performed by MM. The first draft of the manuscript was written by $\mathrm{HH}$. All authors revised and commented on the previous version of the manuscript. All authors have read and approved the manuscript.

\section{Funding}

Nil. The study was totally funded by the authors.

\section{Availability of data and materials}

The datasets used and/or analyzed during the current study are available from the corresponding author on reasonable request.

\section{Ethics approval and consent to participate}

The study was approved by local ethical committee, Faculty of medicine, Ain Shams University. The date of approval was on 9-5-2018. A written informed consent was obtained from all participants.

\section{Consent for publication}

A written informed consent for publication was obtained from all participants.

\section{Competing interests}

The authors declare that they have no competing interests. 


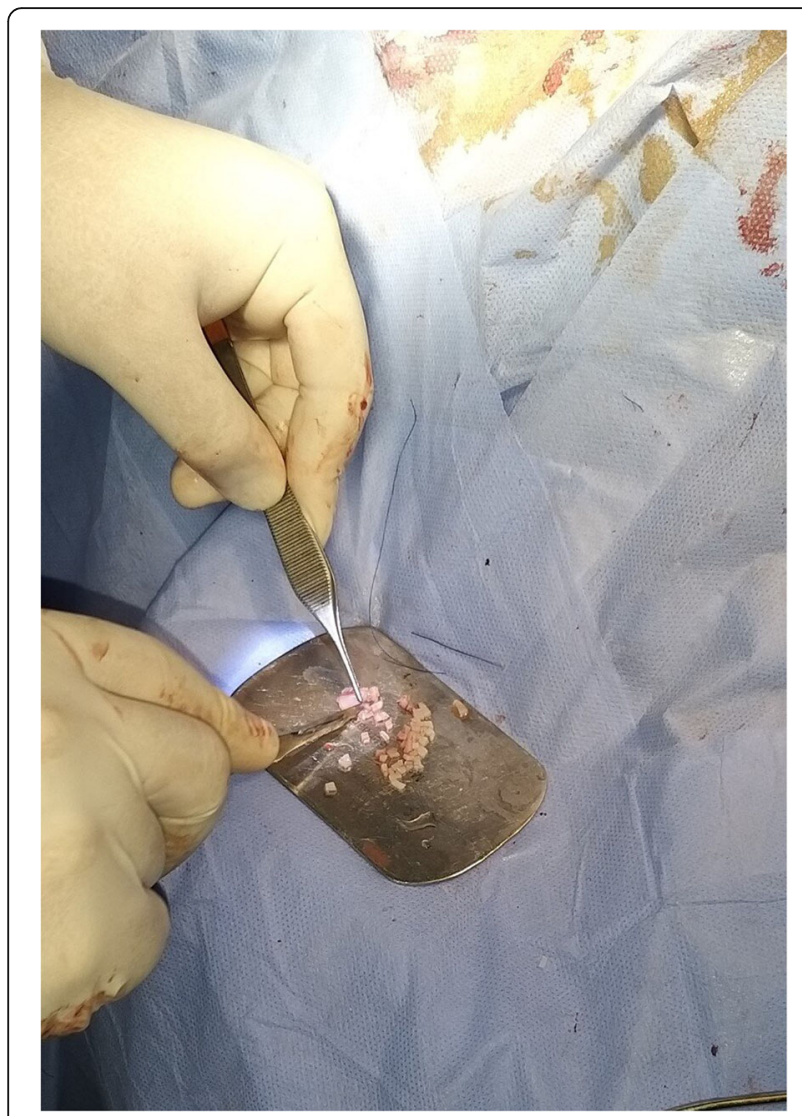

Fig. 7 Case no. (6): 1—open rhinoplasty. 2-septoplasty. 3-dorsal cartilaginous hump removal by blade no. 11. 4-rasping of dorsal bony hump. 5-osteotomies. 6-columellar strut. 7—spreader graft for correct of dorsal nasal malalignment. 8-suturing the nasal septum with two upper lateral cartilages to avoid open roof deformity. 9-filling the small deficit of nasal dorsum with FDC

Received: 17 June 2020 Accepted: 6 November 2020

Published online: 01 December 2020

\section{References}

1. Daniel RK (2002) Rhinoplasty: an atlas of surgical techniques. Springer, New York

2. Kreymerman PA, Fardo D (2008) Rhinoplasty augmentation: treatment Plastic Surg 25:236-242

3. Araco A, Gravante G, Araco F, Castri F, Delogu D, Filingeri V, Casciani CU, Cervelli V (2006) Autologous cartilage graft rhinoplasties. Aesthet Plast Surg 30(2):169-174

4. Bateman N, Jones NS (2000) Retrospective review of augmentation rhinoplasties using autologous cartilage grafts. J Laryngol Otol 114(7):514518

5. Oreroglu AR, Cakir B, Akan M (2014) Bone dust and diced cartilage combined with blood glue: a practical technique for dorsum enhancement. Aesthet Plast Surg 38(1):90-94

6. Kreutzer C, Hoehne J, Gubisch W, Rezaeian F, Haack S (2017) Free diced cartilage: a new application of diced cartilage grafts in primary and secondary rhinoplasty. Plast Reconstr Surg 140(3):461-470

7. Stewart MG, Witsell DL, Smith TL, Weaver EM, Yueh B, Hannley MT (2004) Development and validation of the nasal obstruction symptom evaluation (NOSE) scale. Otolaryngol Head Neck Surg 130:157-163

8. Alsarraf R (2000) Outcomes research in facial plastic surgery: a review and new directions. Aesthet Plast Surg 24(3):192-197
9. Amer MA, Kabbash IA, Younes A, Elzayat S, Tomoum MO (2017) Validation and cross-cultural adaptation of the arabic version of the nasal obstruction symptom evaluation scale. Laryngoscope 127(11):2455-2459

10. Mohamed FA, Tahssen H (2017) A study of rhinoplasty outcome evaluation (ROE) in endonasal aesthetic rhinoplasty in secondary cases. Adv Plast Reconstr Surg 2(1):152-158

11. Cakmak O, Buyuklu F (2007) Crushed cartilage grafts for concealing irregularities in rhinoplasty. Arch Facial Plast Surg 9(5):352-357

12. Daniel RK, Calvert JW (2004) Diced cartilage grafts in rhinoplasty surgery Plast Reconstr Surg 113(7):2156-2171

13. Kelly MH, Bulstrode NW, Waterhouse N (2007) Versatility of diced cartilagefascia grafts in dorsal nasal augmentation. Plast Reconstr Surg 120(6):16541659

14. Bullocks JM, Echo A, Guerra G, Stal S, Yuksel E (2011) A novel autologous scaffold for diced-cartilage grafts in dorsal augmentation rhinoplasty. Aesthet Plast Surg 35(4):569-579

15. Powell N, Humphreys B (1984) Proportions of the aesthetic face. ThiemeStratton, New York

16. Miller TA (1988) Temporalis fascia grafts for facial and nasal contour augmentation. Plast Reconstr Surg 81(4):524-533

17. Hoehne J, Gubisch W, Kreutzer C, Haack S (2016) Refining the nasal dorsum with free diced cartilage. Facial Plastic Surg 32(4):345-350

18. Erol $\bigcirc 0$ (2017) Discussion: free diced cartilage: a new application of diced cartilage grafts in primary and secondary rhinoplasty. Plast Reconstr Surg 140(3):471-473

19. Kahveci OK, Miman MC, Yucel A, Yucedag F, Okur E, Altuntas A (2012) The efficiency of NOSE obstruction symptom evaluation (NOSE) scale on patients with nasal septal deviation. Auris Nasus Larynx 39(3):275-279

20. Gerecci D, Casanueva FJ, Mace JC, Annen A, Barrett DM, Kim MM, Wang TD, Smith TL and Loyo M (2019) Nasal obstruction symptom evaluation (NOSE) score outcomes after septorhinoplasty. Laryngoscope. 129(4): 841846. doi: https://doi.org/10.1002/lary.27578. Epub 2018 Dec 21

21. Alsarraf R, Larrabee WF, Anderson S, Murakami CS, Johnson CMJ (2001) Measuring cosmetic facial plastic surgery outcomes. A pilot study. Arch Facial Plast Surg 3:198-201

22. Arima LM, Velasco LC, Tiago RS (2011) Crooked nose: outcome evaluations in rhinoplasty. Braz J Otorhinolaryngol 77(4):510-515. https://doi.org/10. 1590/s1808-86942011000400016

\section{Publisher's Note}

Springer Nature remains neutral with regard to jurisdictional claims in published maps and institutional affiliations.

\section{Submit your manuscript to a SpringerOpen ${ }^{\odot}$ journal and benefit from:}

- Convenient online submission

- Rigorous peer review

- Open access: articles freely available online

High visibility within the field

- Retaining the copyright to your article

Submit your next manuscript at $\boldsymbol{\nabla}$ springeropen.com 